\title{
Editorial
}

Journal of Innate

Immunity

\section{The Multiple Faces of Host Defence Peptides and Proteins}

\author{
Artur Schmidtchen \\ Division of Dermatology, Department of Clinical Sciences, Lund University, Biomedical Center, Lund, Sweden
}

Antimicrobial peptides (AMPs) constitute an extensive family of molecules which provide a first line of defence against invading microbes at epithelial surfaces as well as in blood [1-5]. It has become increasingly evident that many AMPs, such as defensins and cathelicidins, are multifunctional and mediate multiple immunomodulatory effects $[6,7]$. This has motivated the broader definition, host defence peptides (HDPs), for these members of the innate immune system. The family of host defence molecules has recently been shown to encompass not only 'classic' AMPs, but also various bioactive peptides and proteins with antimicrobial activities. Thus, a complex picture is emerging where a temporospatial expression of multiple host defence molecules not only mediates a direct interaction with microbes, but where there is simultaneous 'tuning' and control of various components of adaptive and innate immunity. In this issue of the Journal of Innate Immunity, we focus on various aspects of the intriguing multifunctionality of HDPs. The binding of AMPs to lipopolysaccharide (LPS) is a critical step in their antimicrobial action, but this interaction also implicates immunomodulatory roles. In the first review, contributed by Pulido et al. [8], the various mechanisms underlying the antiendotoxic effects of many AMPs are described in detail. By neutralizing circulating endotoxins,
AMPs can reduce proinflammatory responses, hence preventing the cytokine storm and organ damage seen during sepsis.

AMPs may also act by other more subtle cell-specific mechanisms. For example, they may interfere with the Toll-like receptor 4 (TLR4) recognition system by disturbing the local membrane environment of the receptor, modifying its activation state, and leading to the suppression of cytokine production and the modulation of the inflammatory response. Increased knowledge of the structural prerequisites for LPS and/or cell interactions could lead to the development of new drugs to neutralize and modulate the endotoxic activities of LPS. $\beta$-Defensins comprise one of the largest groups of HDPs, found in the skin and on other epithelial surfaces. These cysteineconstrained peptides selectively kill many different microbes, including bacteria, yeasts and viruses. In recent years, multiple other roles for defensins have been uncovered. Semple and Dorin [9] review the recent advances on this important family of HDPs.

With respect to their immunomodulatory actions, $\beta$ defensins may bind to several cell-surface receptors and enhance the immune response. Recent data, however, indicate that these molecules may also attenuate the immune response. Hence, it is apparent that defensins ex-

\section{KARGER}

Fax +4161306 1234

E-Mail karger@karger.ch

www.karger.com
(C) 2012 S. Karger AG, Basel

$1662-811 X / 12 / 0044-0325 \$ 38.00 / 0$

Accessible online at:

www.karger.com/jin
Prof. Artur Schmidtchen

Division of Dermatology, Department of Clinical Sciences

Lund University, Biomedical Center, Tornavägen 10

SE-22184 Lund (Sweden)

Tel. +46 46222 4522, E-Mail artur.schmidtchen@med.lu.se 
hibit both pro-inflammatory and anti-inflammatory effects, likely depending on their concentration levels and type of biological context, disease state and pathogen exposure. Apart from their immunomodulatory actions, defensins are also involved in fertility, development, wound healing and cancer, which further illustrate the multifunctionality of these abundant host defence molecules. The eccrine sweat glands in the skin secrete dermcidin-derived AMPs, demonstrating that sweat constitutes an intrinsic part of human innate immunity. In the review by Schittek [10], the evolution, genetic organization, processing and expression as well as functional aspects of dermcidins are discussed in depth. Notably, this peptide family may also exert multiple other roles, and is involved in the activation of pro-inflammatory keratinocyte responses, as well as in carcinogenesis. Studies on cathelicidins and their nonantimicrobial roles have in- spired the discovery and definition of new classes of peptides with mainly immunoregulatory functions.

Choi et al. [11] review the multiple roles of such HDPs, with a focus on the cathelicidin, LL-37, as well as on new synthetic immune defence regulators and their therapeutic potential. Also discussed in this review are emerging concepts of specific HDPs in immune-mediated inflammatory diseases, including the potential use of immune defence regulators as new therapeutics for inflammatory disorders. Finally, the multifunctionality of HDPs is illustrated by the communication by Abdillahi et al. [12], showing that the abundant matrix protein collagen VI contains epitopes, such as the von Willebrand factor domains, which encode for antimicrobial activity against streptococci. Their results suggest that extracellular matrices may harbor cryptic epitopes exerting antimicrobial activities.

\section{References}

$>1$ Boman HG: Antibacterial peptides: basic facts and emerging concepts. J Intern Med 2003;254:197-215.

-2 Zasloff M: Antimicrobial peptides of multicellular organisms. Nature 2002;415:389395.

3 Lehrer RI, Ganz T: Defensins of vertebrate animals. Curr Opin Immunol 2002;14:96102.

4 Yeaman MR, Yount NY: Unifying themes in host defence effector polypeptides. Nat Rev Microbiol 2007;5:727-740.

$>5$ Schroder JM, Harder J: Antimicrobial skin peptides and proteins. Cell Mol Life Sci 2006; 63:469-486.
-6 Yang D, Biragyn A, Hoover DM, Lubkowski J, Oppenheim JJ: Multiple roles of antimicrobial defensins, cathelicidins, and eosinophilderived neurotoxin in host defense. Annu Rev Immunol 2004;22:181-215.

$>7$ Bowdish DM, Davidson DJ, Scott MG, Hancock RE: Immunomodulatory activities of small host defense peptides. Antimicrob Agents Chemother 2005;49:1727-1732.

$>8$ Pulido D, Nogués MV, Boix E, Torrent M: Lipopolysaccharide neutralization by antimicrobial peptides: a gambit in the innate host defense strategy. J Innate Immun 2012; 4:327-336.
9 Semple F, Dorin JR: $\beta$-Defensins: multifunctional modulators of infection, inflammation and more. J Innate Immun 2012;4:337348

10 Schittek B: The multiple facets of dermcidin in cell survival and host defense. J Innate Immun 2012;4:349-360.

11 Choi KY, Chow LN, Mookherjee N: Cationic host defence peptides: multifaceted role in immune modulation and inflammation. J Innate Immun 2012;4:361-370.

12 Abdillahi SM, Balvanović S, Baumgarten M, Mörgelin M: Collagen VI encodes antimicrobial activity: novel innate host defense properties of the extracellular matrix. J Innate Immun 2012;4:371-376. 